\title{
Variation in Flavonoid Composition and Radical-Scavenging Activity in Ginkgo biloba L. due to the Growth Location and Time of Harvest
}

\author{
Laura Rimkiene, ${ }^{1}$ Asta Kubiliene, ${ }^{1}$ Andrejus Zevzikovas, ${ }^{1}$ \\ Daiva Kazlauskiene, ${ }^{1}$ and Valdas Jakstas ${ }^{2}$ \\ ${ }^{1}$ Department of Analytical and Toxicological Chemistry, Lithuanian University of Health Sciences, \\ Sukileliu 13, LT-50166 Kaunas, Lithuania \\ ${ }^{2}$ Department of Pharmacognosy, Lithuanian University of Health Sciences, Sukileliu 13, LT-50166 Kaunas, Lithuania
}

Correspondence should be addressed to Laura Rimkiene; laura.rimkiene@lsmuni.lt

Received 14 June 2017; Revised 12 August 2017; Accepted 30 August 2017; Published 12 October 2017

Academic Editor: Ángel A. Carbonell-Barrachina

Copyright (C) 2017 Laura Rimkiene et al. This is an open access article distributed under the Creative Commons Attribution License, which permits unrestricted use, distribution, and reproduction in any medium, provided the original work is properly cited.

\begin{abstract}
The aim of our research is to investigate the qualitative and quantitative composition and antioxidant activity of flavonoids in leaf samples of Ginkgo biloba L. (G. biloba) growing in Lithuania and also to provide practical recommendations for the pharmaceutical industry to determine the optimum harvesting time and growth location of $G$. biloba leaves. The obtained results indicate that the growth location and time of sample collection have a significant influence $(p \leq 0.05)$ on the content of active compounds. July and August are the best months to harvest G. biloba leaves for industry. To ensure the rational collection of G. biloba raw material, the location of plantations is recommended in the western and southwestern phytoregions. The obtained results also indicate that the flavonoid content in G. biloba leaf has a significantly positive correlation $(r=0.952, p \leq 0.001)$ with antioxidant activity. The aqueous acetonic extracts from green leaves scavenge radicals to a greater degree than those from yellow Ginkgo leaves. The results of this investigation provide information regarding the most suitable Lithuanian growing location to produce G. biloba with an optimized content of health-promoting compounds.
\end{abstract}

\section{Introduction}

G. biloba is one of the most popular medicinal plants. Active compounds in Ginkgo extract possess antioxidant [1-3], antiasthmatic [4], and wound-healing properties [5], improve blood circulation, discourage clot formation, reinforce the walls of capillaries, and protect nerve cells from harm when deprived of oxygen [6]. Due to its notable pharmacological effects, G. biloba is widely used for the treatment of Alzheimer's disease [7], concentration difficulties, and memory impairment [8], cerebral insufficiency [9], intermittent claudication [10], vertigo [11], and tinnitus [12].

The standardization of G. biloba leaf extract, which is used in the production of medicines, is problematic due to the insufficiently revealed relation between accumulated compounds and a therapeutic response. The composition of the primary plant material becomes significant in the production of nonstandardized phytopharmaceutical products. Pharmaceutical companies prefer using cultivated plants instead of wild-harvested plants because they show smaller variation in their constituents. Furthermore, when medicinal plants are produced by cultivation, the main secondary metabolites can be monitored, permitting the definition of the best period for harvesting [13]. No additives regulating the compositional variation are used in the preparation of the target group of extracts-quantified extracts and final pharmaceutical products. Therefore, the selection of a suitable extraction solvent and procedure, as well as the preparation of appropriately constituted plant raw material, is important in order to ensure a reproducible quality of herbal medicinal products. Research in changing quantities of bioactive compounds of the plants that are grown in specific production areas is applied in order to reduce variation in the possible composition and the therapeutic response. 
The content of bioactive compounds differs during the plant growth period and can be influenced by growing region, cultivation sources, and climate [14], temperature [15], light, water availability, and agricultural techniques [16]. Thus, it is important to study the seasonal differences in the contents and bioactivity of active compounds. There are few reports on the effect of sunrays on plant physiology, phenological changes with spatial variation, content of phenolic compounds, and free radical-scavenging activity within the vegetative period $[17,18]$. Some studies have reported different contents of flavonoids and phenolic compounds in G. biloba leaves, but all of the work was done with trees that were cultivated in warm temperate climates.

Literature sources provide little data about the phenolic compounds in G. biloba plants and the quality of the raw material growing under the climatic conditions of the Baltic Nordic region. Therefore, the aim of our research is to investigate the qualitative and quantitative composition and antioxidant activity of flavonoids in leaf samples of G. biloba growing in Lithuania and also to present a reference for industry to determine the optimum collection time and growing location of $G$. biloba leaves.

\section{Materials and Methods}

2.1. Plant Material. In order to obtain different growing regions and harvest time, G. biloba phenotypes from five different collections were studied (Table 1). The study sample comprised 25-30 healthy, fully developed leaves collected from the middle part of current shoot situated at the east side of each tree. Leaves were collected from different regions of Lithuania every month between June 25 and October 25, 2014. The leaves that were collected between June 25 and August 25 were green, while those that were collected on September 25 th were green and yellow and those that were collected on October 25th were yellow. The temperature during the vegetative period was close to the annual averages. There were no extremes that could affect normal development of $G$. biloba trees. Daily minimum temperatures indicate autumn frosts which were recorded 6 nights at the end of September to the beginning of October.

The raw material was air-dried at room temperature $\left(20-25^{\circ} \mathrm{C}\right)$ until reaching air-dried condition in well ventilated room, protected from direct sun rays. Loss on drying before the analysis was determined by applying the method indicated in the European Pharmacopoeia. The research results were converted to absolutely dry plant material considering the obtained data of sample shrinkage.

2.2. Reagents and Standards. HPLC-grade methanol was supplied by Carl Roth GmbH \& Co (Karlsruhe, Germany); the ethanol was produced by Stumbras (Kaunas, Lithuania). The acetone (HPLC grade), hydrochloric acid (37\%), potassium persulphate (99\%), 2,2'-Azino-bis(3-ethylbenzothiazoline6-sulphonic acid) diammonium salt (ABTS, 98\%), and orthophosphoric acid (85\%) were purchased from SigmaAldrich GmbH (Buchs, Switzerland). Trolox (98\%) was received from Fluka Chemie (Buchs, Switzerland). The reference substances kaempferol (99\%) and isorhamnetin (99\%) were purchased from Extrasynthèse (Genay, France), and quercetin (>99\%) was purchased from HWI ANALYTIK $\mathrm{GmbH}$ (Ruelzheim, Germany). Ultrapure water was purified with a Millipore water cleaning system (Bedford, USA).

2.3. Preparation of Extracts. Samples of G. biloba leaves were prepared according to the method described in the European Pharmacopoeia monograph (Ph. Eur. 01/2011:1828) [19] of Ginkgo leaf (Ginkgonis folium). The extracts were produced by weighing $2.5 \mathrm{~g}$ of material (precise weight) and adding the solvent up to a total volume of $50.0 \mathrm{~mL}$. The samples of raw material were extracted in a $60 \%$ acetone/water mixture (v/v) by heating under a reflux condenser twice for $30 \mathrm{~min} .50 .0 \mathrm{~mL}$ of prepared solution was evaporated till the elimination of acetone. Remaining extract was transferred to $50.0 \mathrm{~mL}$ vial, rinsed with $30.0 \mathrm{~mL}$ of methanol and $4.4 \mathrm{~mL}$ of hydrochloric acid, and diluted with water to the $50.0 \mathrm{~mL}$ mark. $10.0 \mathrm{~mL}$ of the supernatant liquid was placed in a $10.0 \mathrm{~mL}$ brown-glass vial and closed with a rubber seal and aluminium cap and heated on the water-bath for $25 \mathrm{~min}$. The extracts were filtered through $0.22-\mu \mathrm{m}$ nylon syringe filters (Carl Roth $\mathrm{GmbH} \&$ Co. KG, Germany).

2.4. HPLC-PDA Analysis. The HPLC equipment system consisted of a Waters 2695 chromatograph (Waters Corporation, Milford, USA) that was equipped with a Waters 2998 photodiode array detector (Waters Corporation, Milford, USA). The chromatographic separation was carried out using a $150 \times$ $4.6 \mathrm{~mm}, 5-\mu \mathrm{m}$ ACE C18 column (Advanced Chromatography Technologies, Aberdeen, Scotland) that was thermostated at $25^{\circ} \mathrm{C}$. The injection volume was $10 \mu \mathrm{L}$, and the elution flow rate was $1.0 \mathrm{~mL} \mathrm{~min}^{-1}$. A binary mobile phase with a gradient elution was used. Eluent A consisted of water (HPLC grade) containing $0.3 \mathrm{~g} \mathrm{~L}^{-1}$ orthophosphoric acid $(\mathrm{pH} 2.0)$ and eluent $\mathrm{B}$ consisted of methanol. The following gradient was used: $0 \mathrm{~min}$ to $1 \mathrm{~min}$ with $60 \% \mathrm{~A}$ and $40 \% \mathrm{~B} ; 1 \mathrm{~min}$ to 20 min from $60 \%$ to $45 \%$ A and from $40 \%$ to $55 \%$ B; 20 min to $21 \mathrm{~min}$ from $45 \%$ to $0 \% \mathrm{~A}$ and from $55 \%$ to $100 \% \mathrm{~B} ; 21 \mathrm{~min}$ to $25 \mathrm{~min}$ with an isocratic elution of $100 \% \mathrm{~B}$; and $25 \mathrm{~min}$ to $30 \mathrm{~min}$ from $0 \%$ to $60 \% \mathrm{~A}$ and from $100 \%$ to $40 \% \mathrm{~B}$.

Validation of the HPLC-PDA method was determined according to the following parameters: specificity, precision, limit of detection, and limit of quantification (Table 2).

2.5. The Identification and Quantification of Flavonoid. Quercetin, kaempferol, and isorhamnetin are assigned as markers that can be used to evaluate the quality and authenticity of $G$. biloba extracts and dosage forms [20, 21]. Therefore, as described above, aglycones, which are used as markers, were chosen for our further investigations. The confirmation of the chromatographic peak (quercetin, kaempferol, and isorhamnetin) identity was achieved by comparing the retention times and spectral characteristics $(\lambda=200-600 \mathrm{~nm})$ of the eluting peaks with those of reference compounds.

The stock solutions of reference standards were prepared by dissolving them in methanol. Calibration curves were established by diluting the stock solutions with methanol in appropriate quantities. The quantities of compounds 
TABLE 1: Geographical coordinates of the Ginkgo biloba accessions that were harvested in Lithuania.

\begin{tabular}{|c|c|c|c|c|c|}
\hline \multirow{2}{*}{ Sample number } & \multirow{2}{*}{ Localization } & \multirow{2}{*}{ Regions } & \multicolumn{2}{|c|}{ Geographical coordinates } & \multirow{2}{*}{ Voucher numbers } \\
\hline & & & Latitude $(\mathrm{N})$ & Longitude (E) & \\
\hline 1 & Siauliai & Northern & $55^{\circ} 55^{\prime} 20^{\prime \prime}$ & $23^{\circ} 19^{\prime} 0^{\prime \prime}$ & $2002 / 0925$ \\
\hline 2 & Klaipeda & Western & $55^{\circ} 39^{\prime} 40^{\prime \prime}$ & $21^{\circ} 10^{\prime} 30^{\prime \prime}$ & $2005 / 0926 ; 1997 / 0304$ \\
\hline 3 & Kaunas & Central & $54^{\circ} 53^{\prime} 50^{\prime \prime}$ & $23^{\circ} 53^{\prime} 10^{\prime \prime}$ & $1936 / 0503$ \\
\hline 4 & Vilkaviskis & Southwestern & $54^{\circ} 38^{\prime} 50^{\prime \prime}$ & $23^{\circ} 2^{\prime} 10^{\prime \prime}$ & $2006 / 0702$ \\
\hline 5 & Lazdijai & Southern & $54^{\circ} 14^{\prime} 10^{\prime \prime}$ & $23^{\circ} 31^{\prime} 0^{\prime \prime}$ & $2008 / 0625$ \\
\hline
\end{tabular}

TABLE 2: Analytical characteristics of the HPLC method validation data.

\begin{tabular}{lcccccc}
\hline Standards & $\begin{array}{c}\text { Intraday RSD (\%) } \\
(n=5)\end{array}$ & $\begin{array}{c}\text { Interday RSD (\%) } \\
(n=5)\end{array}$ & $R^{2}$ & Regression equation & LOD $\left(\mu \mathrm{g} \mathrm{ml}^{-1}\right)$ & LOQ $\left(\mu \mathrm{g} \mathrm{ml}^{-1}\right)$ \\
\hline Quercetin & 0.62 & 0.80 & 0.995 & $Y=9.86 \cdot 10^{6} \cdot x+3.12 \cdot 10^{4}$ & 0.04 & 0.16 \\
Kaempferol & 0.85 & 1.46 & 0.998 & $Y=2.68 \cdot 10^{7 \cdot x+8.09 \cdot 10^{3}}$ & 0.10 & 0.30 \\
Isorhamnetin & 0.28 & 0.33 & 0.999 & $Y=2.15 \cdot 10^{7} x+3.76 \cdot 10^{3}$ & 0.20 & 0.80 \\
\hline
\end{tabular}

$T_{R}$ : retention time, RSD: relative standard deviation, $R^{2}$ : correlation coefficient, LOD: limit of detection, and LOQ: limit of quantitation.

were calculated from an external standard calibration curves established on six concentrations in the following range: $0.4-250 \mu \mathrm{g} \mathrm{mL}^{-1}$ for quercetin, $0.4-25 \mu \mathrm{g} \mathrm{mL}^{-1}$ for kaempferol, and $0.4-25 \mu \mathrm{g} \mathrm{mL}^{-1}$ for isorhamnetin. Each sample was analysed in triplicate and the mean value was used for calculation. The concentration of compounds was expressed as $\mathrm{mg} \mathrm{g}^{-1}$ dry mass (DM).

2.6. ABTS Postcolumn Assay. The online HPLC-ABTS assay was carried out using the method described by Marksa et al. [22]. The flow rate of the individual solution was set at $0.5 \mathrm{~mL} \mathrm{~min}^{-1}$. A reaction coil that was made of Teflon (TFE) of $3 \mathrm{~m}$ in length and $0.25 \mathrm{~mm}$ i.d. was used. The reactor temperature was set at $50^{\circ} \mathrm{C}$. The product chromatograms after ABTS postcolumn reaction were registered at $650 \mathrm{~nm}$ using a Waters 2487 dual $\lambda$ absorbance (UV/Vis) detector (Waters Corporation, Milford, USA). The calibration curve formed was equivalent to standard Trolox and was expressed by following quadratic equation: $R^{2}=0.999\left(Y=3.00 \cdot 10^{7}\right.$. $\left.x+3.48 \cdot 10^{4}\right)$.

The postcolumn reaction is an extension of the HPLC method. At the time of postcolumn reaction, no distribution is taking place; previously separated analytes pass through the reactor. Therefore, the main HPLC separation parameters do not apply for postcolumn assay validation [23]. The HPLC separation method is validated separately. HPLCABTS assay validation in this work was determined according to intraday and interday precision, minimum detectable concentration, minimum detectable amount, and linearity (Table 3). Validation was based on the area assessment of negative peaks of standard compounds in a postcolumn chromatogram. The precision of the postcolumn method was demonstrated by performing five replicate nonconsecutive injections of the reference standard solutions on the same day (intraday) and on three different days (interday). The RSD coefficient for repeatability and intermediate precision did not exceed $3.0 \%$. Such precision is acceptable for all the needs of pharmaceutical analysis and is suitable for the quantitative evaluation of antioxidant markers. All 4 antioxidant compounds showed significant linear regression with a determination coefficient higher than 0.99 for the postcolumn assay. The ABTS postcolumn assay is fully linear over the concentration range that was tested.

2.7. Antioxidant Activity Assessment. Calibration curves of Trolox (concentrations range: $1.00-160.00 \mu \mathrm{g} \mathrm{mL}^{-1}$ ) were made in the ABTS postcolumn assay. The radical-scavenging capacity of antioxidant active compounds in G. biloba extracts was expressed as $\mu \mathrm{mol}$ Trolox equivalent (TE) per gram of leaves. TE was calculated by the following formula:

$$
\mathrm{TE}\left(\mu \mathrm{molg}^{-1}\right)=c \times \frac{V_{\text {samp }}}{m_{\text {samp }}},
$$

where $c$ is the concentration of Trolox established from the calibration curve $(\mu \mathrm{M}), V_{\text {samp }}$ is the volume of herbal raw material extract (L), and $m_{\text {samp }}$ is the weight (precise) of herbal raw material $(\mathrm{g})$.

2.8. Statistical Analysis. The statistical package SPSS 20.0 (SPSS Inc., Chicago, USA) was used for statistical processing and data evaluation. All of the determinations were made in triplicate, and the means and standard errors were calculated. An analysis of variance (ANOVA) was performed to assess the effect of growth location and time of harvest on the levels of flavonoids. The strength of effect is given in partial etasquared $\left(\eta^{2}\right)$. The post hoc comparisons of mean quantities were made using Tukey's HSD (Honest Significant Differences) post hoc test. Differences were considered significant when the $p$ values were less than 0.05 . The growth location and the time of harvest were considered fixed factors. A Pearson correlation coefficient was calculated to evaluate the correlation. 
TABLE 3: Validation characteristics of the ABTS postcolumn assay.

\begin{tabular}{lcccc}
\hline Parameters & & \multicolumn{3}{c}{ ABTS assay } \\
& Trolox & Quercetin & Kaempferol & Isorhamnetin \\
\hline Linearity range $\left(\mu \mathrm{g} \mathrm{ml}^{-1}\right)$ & $1-160$ & $4-74$ & $5-84$ & 1.28 \\
Intraday RSD $(\%)^{\mathrm{a}}$ & 0.10 & 0.92 & 2.30 & 0.25 \\
Interday RSD $(\%)^{\mathrm{a}}$ & 1.77 & 1.51 & 1.46 & 1.15 \\
$\mathrm{LOD}\left(\mu \mathrm{g} \mathrm{ml}^{-1}\right)$ & 0.30 & 2.10 & 4.89 & 2.02 \\
LOQ $\left(\mu \mathrm{g} \mathrm{ml}^{-1}\right)$ & 1.00 & 5.20 & 6.75 \\
\hline
\end{tabular}

RSD: ${ }^{a}$ relative standard deviation, LOD: limit of detection, and LOQ: limit of quantitation.

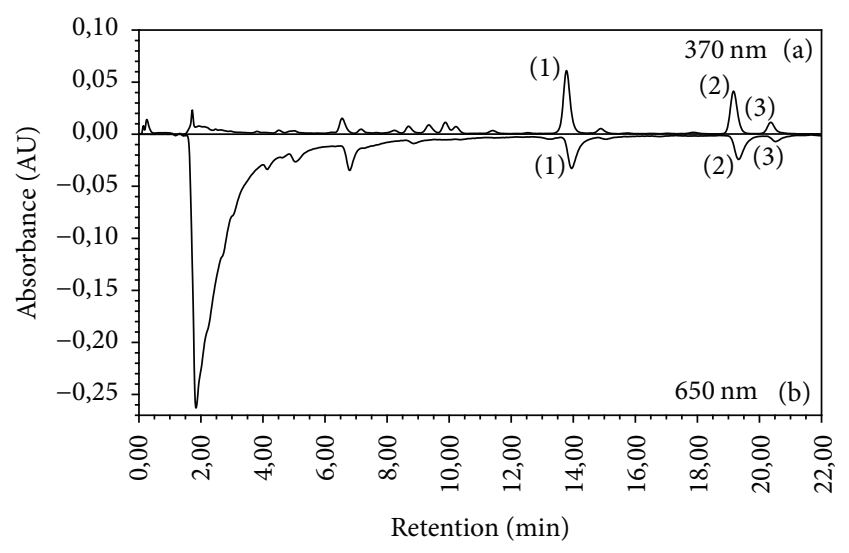

FIGURE 1: Combined chromatograms of Ginkgo biloba leaf extracts: chromatographic elution (a) and postcolumn reaction with ABTS (b) reagent. The numbers refer to the following identified compounds: (1) quercetin, (2) kaempferol, and (3) isorhamnetin.

\section{Results and Discussion}

3.1. Impact of the Collection Growth Location (L), the Time of Harvest (T), and the Interaction between $L$ and $T(L$ $\times$ T) on Flavonoid Content. Quercetin, kaempferol, and isorhamnetin were detected (Figure 1) in all specimens during plant development, but the contents of compounds varied significantly. A dispersion analysis of the received data established that the growth location and harvesting time had a significant influence $(p<0.05)$ on the amount of active compounds that were identified in G. biloba leaves (Table 4).

A dispersion analysis of the research data revealed that the factors identified above had the following influence on individual compounds: $L$ contributed to the majority of isorhamnetin variations at $\eta^{2}=0.575$ and $T$ accounted for the majority of variation in quercetin $\left(\eta^{2}=0.397\right)$ and kaempferol $\left(\eta^{2}=0.722\right)$. According to the statistical data analysis, the $L \times T$ interaction was not significant for all compounds. The $L \times T$ interaction showed a significant contribution to isorhamnetin only at $-\eta^{2}=0.386$ (Table 4 ).

So far, the literature lacks reliable data about the influence of the sample harvesting time and growth location on the accumulation of bioactive compounds in G. biloba. A review of the scientific literature on similar studies of gymnospermous plants suggests that, depending on geographical regions and growth locations, the same gymnospermous tree species demonstrate different reaction to changes in temperature and precipitation. Although gymnospermous trees growth reaction to changes in air temperature and rainfall varies in different geographical regions, the observed general features of growth variations demonstrate the existence of general climatic factors limiting and benefitting tree growth in big territories $[24,25]$. As the time of the year and phytogeographical location are very important in the growth of gymnospermous trees, this work will focus on the influence of these factors on the phytochemical composition of $G$. biloba leaves.

3.2. Flavonoid Changes during Harvest of G. biloba Leaves. In order to clarify the influence of the raw material collecting time on the phytochemical composition of bioactive compounds in G. biloba, there are comprehensive studies on the regularity of compound accumulation in medicinal plant raw materials.

Quercetin dominated in G. biloba leaf samples that were collected during the vegetation period, constituting $64.8-81.5 \%$ of all of the identified flavonoids. Our research data are confirmed by works of other scientists, indicating that quercetin is the dominating component in G. biloba leaf extracts [26]. Significant fluctuations $(p<0.05)$ in the quercetin content from $2.12 \mathrm{mg} \mathrm{g}^{-1}$ to $13.27 \mathrm{mgg}^{-1}$ are observed during the vegetation period (Table 5). The highest contents are established in July $\left(13.27 \pm 0.59 \mathrm{mg} \mathrm{g}^{-1}\right)$ and August $\left(9.10 \pm 0.16 \mathrm{mg} \mathrm{g}^{-1}\right)$ and the lowest contents in June $\left(2.12 \pm 0.04 \mathrm{mg} \mathrm{g}^{-1}\right)$. In the course of vegetation, the quercetin content increases until the end of July (samples 3 and 5 make an exception, where the quercetin content increases until the end of August). Later, smaller amounts of quercetin are maintained until the end of October.

Kaempferol constitutes $13.3-28.9 \%$ of the flavonoid content in the samples. In the course of vegetation, the kaempferol content changes from $0.62 \mathrm{mg} \mathrm{g}^{-1}$ to $2.81 \mathrm{mg} \mathrm{g}^{-1}$. According to the generalized research data, the highest kaempferol contents, as well as those of quercetin, are established in July and August at, respectively, $2.81 \pm 0.10 \mathrm{mg} \mathrm{g}^{-1}$ and $1.74 \pm 0.06 \mathrm{mg} \mathrm{g}^{-1}$, and the lowest contents are in June $\left(0.62 \pm 0.02 \mathrm{mg} \mathrm{g}^{-1}\right)$. Kaempferol and quercetin have similar tendencies of content change during the vegetation period. In G. biloba leaf samples, the kaempferol content increases until the end of July (samples 3 and 5 make an exception, where the kaempferol content increases until the end of August), after which it decreases until the end of October. 
TABLE 4: Effect of the collection growth location, the time of harvest, and interaction between the collection growth location and the time of harvest.

\begin{tabular}{lccccccccc}
\hline Compounds & \multicolumn{3}{c}{$L$} & \multicolumn{3}{c}{$T$} & \multicolumn{3}{c}{$L \times T$} \\
& $F$ ratio & $p$ & $\eta^{2}$ & $F$ ratio & $p$ & $\eta^{2}$ & $F$ ratio & $p$ & 0.121 \\
\hline Quercetin & 10.529 & 0.001 & 0.393 & 10.713 & 0.001 & 0.397 & 1.518 & 0.272 \\
Kaempferol & 11.812 & 0.001 & 0.421 & 42.219 & 0.001 & 0.722 & 1.566 & 0.104 & 0.278 \\
Isorhamnetin & 22.002 & 0.001 & 0.575 & 18.091 & 0.001 & 0.527 & 2.553 & 0.004 & 0.386 \\
\hline
\end{tabular}

Notes. $L$ : growth location, $T$ : the time of harvest, $L \times T$ : interaction between the collection growth location and the time of harvest, $p$ : significant level, $F$ : Fisher's statistics, $p$ : significant differences at $p<0.05$, and $\eta^{2}$ : effect size is given in partial eta-squared.

TABLE 5: Comparison of individual compounds in G. biloba leaf extracts.

\begin{tabular}{|c|c|c|c|c|c|}
\hline \multirow{2}{*}{$\begin{array}{l}\text { Sample } \\
\text { number }\end{array}$} & \multirow{2}{*}{$\begin{array}{l}\text { Growth } \\
\text { location }\end{array}$} & \multirow{2}{*}{ Time of harvest } & \multicolumn{3}{|c|}{ Content $\left(\mathrm{mg} \mathrm{g}^{-1}\right)^{*}$} \\
\hline & & & Quercetin & Kaempferol & Isorhamnetin \\
\hline \multirow{5}{*}{1} & \multirow{5}{*}{ North } & June & $2.22 \pm 0.04^{\mathrm{a}}$ & $0.76 \pm 0.03^{\mathrm{a}}$ & $0.10 \pm 0.01^{\mathrm{a}}$ \\
\hline & & July & $5.98 \pm 0.10^{\mathrm{d}}$ & $1.94 \pm 0.07^{\mathrm{d}}$ & $0.32 \pm 0.03^{\mathrm{d}}$ \\
\hline & & August & $5.22 \pm 0.09^{c}$ & $1.67 \pm 0.05^{\mathrm{c}}$ & $0.22 \pm 0.02^{\mathrm{c}}$ \\
\hline & & September & $5.35 \pm 0.09^{c}$ & $1.63 \pm 0.06^{\mathrm{c}}$ & $0.16 \pm 0.03^{\mathrm{b}}$ \\
\hline & & October & $4.07 \pm 0.07^{\mathrm{b}}$ & $1.20 \pm 0.04^{\mathrm{b}}$ & $0.11 \pm 0.02^{\mathrm{a}}$ \\
\hline \multirow{5}{*}{2} & \multirow{5}{*}{ West } & June & $3.40 \pm 0.29^{\mathrm{a}}$ & $0.73 \pm 0.01^{\mathrm{a}}$ & $0.25 \pm 0.01^{\mathrm{a}}$ \\
\hline & & July & $13.27 \pm 0.59^{\mathrm{b}}$ & $2.19 \pm 0.14^{\mathrm{b}}$ & $1.03 \pm 0.15^{\mathrm{c}}$ \\
\hline & & August & $9.48 \pm 2.21^{\mathrm{ab}}$ & $1.83 \pm 0.22^{\mathrm{b}}$ & $0.82 \pm 0.11^{\mathrm{bc}}$ \\
\hline & & September & $7.52 \pm 1.64^{\mathrm{ab}}$ & $1.79 \pm 0.02^{\mathrm{b}}$ & $0.41 \pm 0.11^{\mathrm{ab}}$ \\
\hline & & October & $7.53 \pm 2.85^{\mathrm{ab}}$ & $1.39 \pm 0.41^{\mathrm{ab}}$ & $0.46 \pm 0.14^{\mathrm{ab}}$ \\
\hline \multirow{5}{*}{3} & \multirow{5}{*}{ Central } & June & $2.12 \pm 0.04^{\mathrm{a}}$ & $0.84 \pm 0.03^{\mathrm{a}}$ & $0.22 \pm 0.01^{\mathrm{a}}$ \\
\hline & & July & $4.65 \pm 0.08^{\mathrm{c}}$ & $1.50 \pm 0.05^{\mathrm{cd}}$ & $0.43 \pm 0.02^{\mathrm{d}}$ \\
\hline & & August & $5.82 \pm 0.10^{\mathrm{d}}$ & $1.64 \pm 0.05^{\mathrm{d}}$ & $0.68 \pm 0.03^{\mathrm{e}}$ \\
\hline & & September & $3.58 \pm 0.06^{\mathrm{b}}$ & $1.40 \pm 0.04^{\mathrm{bc}}$ & $0.37 \pm 0.01^{\mathrm{c}}$ \\
\hline & & October & $3.71 \pm 0.06^{\mathrm{b}}$ & $1.28 \pm 0.04^{\mathrm{b}}$ & $0.28 \pm 0.01^{\mathrm{b}}$ \\
\hline \multirow{5}{*}{4} & \multirow{5}{*}{ Southwest } & June & $2.56 \pm 0.05^{\mathrm{a}}$ & $1.00 \pm 0.04^{\mathrm{a}}$ & $0.18 \pm 0.01^{\mathrm{a}}$ \\
\hline & & July & $7.42 \pm 0.13^{\mathrm{e}}$ & $2.81 \pm 0.10^{\mathrm{e}}$ & $0.44 \pm 0.01^{\mathrm{d}}$ \\
\hline & & August & $4.98 \pm 0.09^{c}$ & $2.06 \pm 0.07^{\mathrm{c}}$ & $0.38 \pm 0.01^{\mathrm{c}}$ \\
\hline & & September & $6.44 \pm 0.11^{\mathrm{d}}$ & $2.36 \pm 0.08^{\mathrm{d}}$ & $0.19 \pm 0.03^{\mathrm{a}}$ \\
\hline & & October & $3.13 \pm 0.05^{\mathrm{b}}$ & $1.40 \pm 0.05^{\mathrm{b}}$ & $0.30 \pm 0.01^{\mathrm{b}}$ \\
\hline \multirow{5}{*}{5} & \multirow{5}{*}{ South } & June & $2.84 \pm 0.05^{\mathrm{a}}$ & $0.62 \pm 0.02^{\mathrm{a}}$ & $0.16 \pm 0.02^{\mathrm{b}}$ \\
\hline & & July & $5.89 \pm 0.10^{\mathrm{b}}$ & $1.46 \pm 0.05^{\mathrm{c}}$ & $0.39 \pm 0.04^{\mathrm{d}}$ \\
\hline & & August & $9.10 \pm 0.16^{\mathrm{d}}$ & $1.74 \pm 0.06^{\mathrm{d}}$ & $0.56 \pm 0.07^{\mathrm{e}}$ \\
\hline & & September & $7.91 \pm 0.14^{c}$ & $1.51 \pm 0.05^{\mathrm{c}}$ & $0.29 \pm 0.06^{\mathrm{c}}$ \\
\hline & & October & $2.97 \pm 0.05^{\mathrm{a}}$ & $0.85 \pm 0.03^{b}$ & $0.11 \pm 0.02^{\mathrm{a}}$ \\
\hline
\end{tabular}

${ }^{*}$ Notes. (1) Different letters in columns show significant difference between the time of harvest for each compound and growth location based on Tukey's HSD test at $p<0.05$; (2) results are presented as the mean \pm standard error $(n=3)$ of the recorded concentrations.

Meanwhile, isorhamnetin constitutes $2.0-8.4 \%$ of the flavonoid content in the samples. The highest contents of this compound are established in July $\left(1.03 \pm 0.15 \mathrm{mg} \mathrm{g}^{-1}\right)$ and August $\left(0.68 \pm 0.03 \mathrm{mg} \mathrm{g}^{-1}\right)$, and the lowest contents are in June $\left(0.10 \pm 0.01 \mathrm{mg} \mathrm{g}^{-1}\right)$ and at the end of vegetation period in October when the leaves turn yellow $\left(0.11 \pm 0.01 \mathrm{mg} \mathrm{g}^{-1}\right)$. The isorhamnetin content increases until the end of July (samples 3 and 5 make an exception, where the isorhamnetin content increases until the end of August) and decreases at the end of September (sample 4 makes an exception, where the isorhamnetin content starts increasing at the end of October).

Our results are confirmed by other research findings that indicate similar trends in the changes in phenolic content throughout the growth season [27]. However, our results differ from other research findings that indicate different trends in the changes of phenolic compounds content throughout the growth season. Kaur et al. [17] state that the difference between the accumulated flavonoid content and raw material harvesting time is not statistically important and 
that quercetin, kaempferol, and isorhamnetin do not show a regular trend with sample collection time.

According to scientific literature, G. biloba leaves, depending on climatic conditions, are harvested in July (the USA), August (China), or September/October (France) [28]. This particular time of harvest is chosen with respect to both the maximum concentration of active constituents and the lowest possible damage to the tree caused by the leaf collection. One of the research objectives is to provide practical recommendations for the pharmaceutical industry to determine the optimum collection time of $G$. biloba leaves. Our research data shows that, due to the maximum concentration of flavonoids, July and August are recommended as appropriate times to harvest leaves of G. biloba for industry. According to scientific literature, the collection of $G$. biloba leaves raw material in October is favourable due to the possibility of collecting more biomass and causing less damage to the tree. The obtained research results enable us to state that collection of G. biloba raw material in October is not appropriate, as a high variation (variation coefficients: quercetin: $88 \%$, kaempferol: $46 \%$, and isorhamnetin: $83 \%$ ) makes it complicated to get plant raw material of replicated composition. High variation increases the possibility of collecting raw material of low quality and makes it difficult to ensure the quality of herbal medicinal products.

\subsection{Flavonoid Analysis of G. biloba Leaves Grown in Different} Geographical Regions. The flavonoid contents in G. biloba leaf samples that were collected in different phytogeographical regions of Lithuania (the northern, western, southern, southwestern, and central parts of Lithuania) have been compared statistically. The results show statistically important differences in the amounts of quercetin, kaempferol, and isorhamnetin that are contained in raw materials.

The application of Tukey's HSD post hoc test has established that raw materials that are collected in western Lithuania contain statistically significantly higher $(p<$ 0.05 ) amounts of quercetin and isorhamnetin than do raw materials that are collected in other parts of Lithuania. According to the results of this test, the raw materials that are collected in southwestern part of Lithuania contain statistically significantly higher $(p<0.05)$ amounts of kaempferol than do raw materials that are collected in other parts of the country.

Statistically significant $(p<0.05)$ differences in the quantitative composition of compounds (according to the quercetin, kaempferol, and isorhamnetin contents in raw materials) in the samples from the same or different regions may be related to the age of the plant. Preliminary studies of the influence of plant age on the accumulation of active compounds have been conducted. The results indicate that the content of the flavonoids in G. biloba leaves from young trees is higher than in those from old trees (results not shown). The amount of flavonoids that accumulated during the vegetation period can also be influenced by climatic factors, plant gender, cultivation conditions, and so on [29].

3.4. Assessment of the Antiradical Activity of Extracts. A correlation between the amount of phenolic compounds and antioxidant activity is established in most scientific studies [30-33]. A strong correlation between phenolic compounds and antiradical activity is also found in previous experiments with $G$. biloba leaves $[34,35]$. In our study, a positive and highly significant correlation $(r=0.952, p<0.001)$ between the flavonoid content in G. biloba leaf and antioxidant activity has been determined. Thus, the results of antioxidant activity assessment follow the regularities that are discussed in the analysis of the quantitative change of phenolic compounds during the vegetation period.

In the course of vegetation, the highest antioxidant activity of quercetin is established in July $\left(9.38 \pm 0.03 \mu \mathrm{mol} \mathrm{g}^{-1}\right)$ and August $\left(8.80 \pm 0.04 \mu \mathrm{molg}^{-1}\right)$ when the leaves accumulate the highest flavonoid contents (Table 6). The lowest antiradical activity of quercetin is established in June $(2.00 \pm$ $\left.0.01 \mu \mathrm{mol} \mathrm{g}^{-1}\right)$. According to our research data, the highest antioxidant activity of kaempferol, as well as quercetin, is established in July and August at, respectively, $8.00 \pm$ $0.08 \mu \mathrm{mol} \mathrm{g}^{-1}$ and $4.72 \pm 0.04 \mu \mathrm{mol} \mathrm{g}^{-1}$ and the lowest in June $\left(1.60 \pm 0.10 \mu \mathrm{mol} \mathrm{g}^{-1}\right)$. Meanwhile, the antioxidant activity tendencies of isorhamnetin differ. The highest isorhamnetin antioxidant activity, as well as quercetin and kaempferol, is established in July $\left(1.90 \pm 0.08 \mu \mathrm{mol} \mathrm{g}^{-1}\right)$ and August $(1.12 \pm$ $0.01) \mu \mathrm{mol} \mathrm{g}^{-1}$, but the lowest was in June and September at, respectively, $0.24 \pm 0.01 \mu \mathrm{mol} \mathrm{g}^{-1}$ and $0.03 \pm 0.00 \mu \mathrm{mol} \mathrm{g}^{-1}$.

According to the research data, during the vegetation period, the antioxidant activity depends on the colour of $G$. biloba leaves. A statistically significant difference $(p<0.05)$ between the amount of flavonoids that accumulate in samples of green and yellow leaves has been established. Our results are confirmed by literature data indicating that the aqueous acetonic and ethanolic extracts from green leaves scavenge radicals to a greater degree compared to those from yellow Ginkgo leaves [33].

The obtained research results allow us to establish that the extracts from $G$. biloba raw material that are collected in the western phytogeographical region have a statistically significantly higher $(p<0.05)$ antioxidant activity than do the extracts from raw materials that are collected in other parts of Lithuania. This result is due to the high amounts of flavonoids in the leaves that are harvested in this region. However, there are no significant differences between the TE values for extracts from the southwest, south, north, and central regions (Table 6).

The results that were obtained during the study will serve to prepare raw plant material that is rich in antioxidants and to predict the antioxidant effects of $G$. biloba leaf extracts in vivo and will be valuable for the quality assessment and standardization of raw plant materials and their products.

\section{Conclusion}

In conclusion, the growth location and time of harvest have a significant effect $(p<0.05)$ on the flavonoid concentration in $G$. biloba. The largest variation in the total flavonoid content is attributed to time of harvest, followed by the growth location. The influence of the mentioned factors on the individual compounds is sequenced as follows: the 
TABLE 6: TE values of G. biloba leaf in ABTS postcolumn assay.

\begin{tabular}{|c|c|c|c|c|c|}
\hline \multirow{2}{*}{ Number of sample } & \multirow{2}{*}{ Growing location } & \multirow{2}{*}{ Time of harvest } & \multicolumn{3}{|c|}{$\mathrm{TE}\left(\mu \mathrm{mol} \mathrm{g}{ }^{-1}\right)$} \\
\hline & & & Quercetin & Kaempferol & Isorhamnetin \\
\hline \multirow{5}{*}{1} & \multirow{5}{*}{ North } & June & $2.08 \pm 0.01^{\mathrm{a}}$ & $1.76 \pm 0.02^{\mathrm{a}}$ & $0.04 \pm 0.01^{\mathrm{a}}$ \\
\hline & & July & $5.76 \pm 0.03^{\mathrm{d}}$ & $5.32 \pm 0.05^{\mathrm{c}}$ & $0.40 \pm 0.02^{\mathrm{d}}$ \\
\hline & & August & $5.12 \pm 0.02^{c}$ & $4.72 \pm 0.04^{\mathrm{bc}}$ & $0.28 \pm 0.01^{c}$ \\
\hline & & September & $5.46 \pm 0.02^{\mathrm{d}}$ & $4.46 \pm 0.04^{\mathrm{b}}$ & $0.18 \pm 0.01^{\mathrm{b}}$ \\
\hline & & October & $4.09 \pm 0.02^{\mathrm{b}}$ & $4.12 \pm 0.04^{\mathrm{b}}$ & $0.06 \pm 0.00^{\mathrm{a}}$ \\
\hline \multirow{5}{*}{2} & \multirow{5}{*}{ West } & June & $3.20 \pm 0.02$ & $1.64 \pm 0.06^{\mathrm{a}}$ & $0.28 \pm 0.04^{\mathrm{a}}$ \\
\hline & & July & $9.38 \pm 0.03$ & $5.86 \pm 0.08^{b}$ & $1.90 \pm 0.08^{\mathrm{b}}$ \\
\hline & & August & $8.94 \pm 0.05$ & $5.12 \pm 0.04^{\mathrm{b}}$ & $1.54 \pm 0.06^{\mathrm{b}}$ \\
\hline & & September & $7.11 \pm 0.01$ & $4.61 \pm 0.11^{\mathrm{b}}$ & $0.45 \pm 0.03^{\mathrm{a}}$ \\
\hline & & October & $8.42 \pm 0.02$ & $4.29 \pm 0.05^{\mathrm{ab}}$ & $1.00 \pm 0.08^{\mathrm{ab}}$ \\
\hline \multirow{5}{*}{3} & \multirow{5}{*}{ Central } & June & $2.00 \pm 0.01^{\mathrm{a}}$ & $1.84 \pm 0.02^{\mathrm{a}}$ & $0.24 \pm 0.01^{\mathrm{a}}$ \\
\hline & & July & $4.52 \pm 0.02^{\mathrm{d}}$ & $4.16 \pm 0.04^{\mathrm{cd}}$ & $0.68 \pm 0.01^{\mathrm{b}}$ \\
\hline & & August & $5.76 \pm 0.03^{\mathrm{e}}$ & $4.64 \pm 0.04^{\mathrm{d}}$ & $1.12 \pm 0.01^{c}$ \\
\hline & & September & $2.92 \pm 0.01^{\mathrm{b}}$ & $3.39 \pm 0.03^{\mathrm{b}}$ & $0.34 \pm 0.01^{\mathrm{a}}$ \\
\hline & & October & $3.97 \pm 0.02^{c}$ & $3.86 \pm 0.03^{b c}$ & $0.26 \pm 0.01^{\mathrm{a}}$ \\
\hline \multirow{5}{*}{4} & \multirow{5}{*}{ Southwest } & June & $2.56 \pm 0.01^{\mathrm{a}}$ & $2.32 \pm 0.02^{\mathrm{a}}$ & $0.16 \pm 0.00^{\mathrm{a}}$ \\
\hline & & July & $6.40 \pm 0.03^{\mathrm{d}}$ & $8.00 \pm 0.07^{\mathrm{d}}$ & $0.68 \pm 0.03^{c}$ \\
\hline & & August & $4.96 \pm 0.02^{c}$ & $5.84 \pm 0.05^{\mathcal{c}}$ & $0.64 \pm 0.02^{c}$ \\
\hline & & September & $6.17 \pm 0.03^{\mathrm{d}}$ & $6.18 \pm 0.05^{\mathrm{c}}$ & $0.23 \pm 0.02^{\mathrm{b}}$ \\
\hline & & October & $4.18 \pm 0.02^{\mathrm{b}}$ & $3.89 \pm 0.03^{\mathrm{b}}$ & $0.25 \pm 0.01^{\mathrm{b}}$ \\
\hline \multirow{5}{*}{5} & \multirow{5}{*}{ South } & June & $2.88 \pm 0.01^{\mathrm{a}}$ & $1.60 \pm 0.10^{\mathrm{a}}$ & $0.16 \pm 0.00^{\mathrm{b}}$ \\
\hline & & July & $5.84 \pm 0.03^{c}$ & $4.04 \pm 0.04^{\mathrm{b}}$ & $0.64 \pm 0.01^{\mathrm{d}}$ \\
\hline & & August & $8.80 \pm 0.04^{\mathrm{e}}$ & $4.72 \pm 0.04^{\mathrm{c}}$ & $0.80 \pm 0.00^{\mathrm{e}}$ \\
\hline & & September & $6.86 \pm 0.03^{\mathrm{d}}$ & $3.62 \pm 0.03^{\mathrm{b}}$ & $0.25 \pm 0.00^{c}$ \\
\hline & & October & $3.42 \pm 0.02^{\mathrm{b}}$ & $1.98 \pm 0.02^{\mathrm{a}}$ & $0.03 \pm 0.00^{\mathrm{a}}$ \\
\hline
\end{tabular}

Notes. (1) Different letters on columns show significant difference between time of harvest for each compound and growing location based on Tukey's HSD test at $p<0.05$; (2) results are presented as the mean \pm standard error $(n=3)$ of the recorded concentrations.

growth location contributes to the majority of the variation in isorhamnetin, while the time of harvest accounts for the majority of variation in quercetin and kaempferol. According to the data, due to the maximum concentration of flavonoids, July and August are recommended as appropriate times to harvest leaves of G. biloba for industry. Among the different cultivation sources, G. biloba trees that are cultivated in the western agroclimatic region of Lithuania accumulate a higher content of quercetin and isorhamnetin; meanwhile, the samples from the southwest region contain the highest amount of kaempferol. To ensure the rational harvesting of G. biloba raw material, considering the optimal cultivation area, the above-mentioned phytoregions are recommended to increase culture collections.

\section{Conflicts of Interest}

The authors declare that there are no conflicts of interest regarding the publication of this paper.

\section{References}

[1] Z. Wang, J. Zhang, T. Ren, and Z. Dong, "Targeted metabolomic profiling of cardioprotective effect of Ginkgo biloba L. extract on myocardial ischemia in rats," Phytomedicine, vol. 23, no. 6 , pp. 621-631, 2016.

[2] X.-P. Ding, J. Qi, Y.-X. Chang, L.-L. Mu, D.-N. Zhu, and B.-Y. Yu, "Quality control of flavonoids in Ginkgo biloba leaves by highperformance liquid chromatography with diode array detection and on-line radical scavenging activity detection," Journal of Chromatography A, vol. 1216, no. 11, pp. 2204-2210, 2009.

[3] J. Wang, M. Zheng, L. Chen et al., "Rapid screening, separation, and detection of hydroxyl radical scavengers from total flavonoids of Ginkgo biloba leaves by chromatography combined with molecular devices," Journal of Separation Science, vol. 39, no. 21, pp. 4158-4165, 2016.

[4] V. S. Panda and S. R. Naik, "Cardioprotective activity of Ginkgo biloba Phytosomes in isoproterenol-induced myocardial necrosis in rats: a biochemical and histoarchitectural evaluation," Experimental and Toxicologic Pathology, vol. 60, no. 4-5, pp. 397-404, 2008.

[5] K. L. Bairy and C. M. Rao, "Wound healing profiles of Ginkgo biloba," Journal of Natural Remedies, vol. 1, pp. 25-27, 2001.

[6] F. Q. Wang, J. L. Yan, X. Y. Wang, and G. Shan, "Optimization and simulation study on central urban CBD intersection in group city," Journal of Shandong University of Technology, vol. 21, no. 4, pp. 27-39, 2007 (Chinese).

[7] Y. J. Park, H. Y. Ahn, H. R. Kim, K. H. Chung, and S. M. Oh, "Ginkgo biloba extract EGb 761-mediated inhibition of 
aromatase for the treatment of hormone-dependent breast cancer," Food and Chemical Toxicology, vol. 87, pp. 157-165, 2016.

[8] F. Xu, R. Cai, S. Cheng, H. Du, Y. Wang, and S. Cheng, "Molecular cloning, characterization and expression of phenylalanine ammonia-lyase gene from Ginkgo biloba," African Journal of Biotechnology, vol. 7, no. 6, pp. 721-729, 2008.

[9] M. Wang, E. J. Carrell, A. G. Chittiboyina et al., "Concurrent supercritical fluid chromatographic analysis of terpene lactones and ginkgolic acids in Ginkgo biloba extracts and dietary supplements," Analytical and Bioanalytical Chemistry, vol. 408, no. 17, pp. 4649-4660, 2016.

[10] B. Ahlemeyer and J. Krieglstein, "Neuroprotective effects of Ginkgo biloba extract," Cellular and Molecular Life Sciences, vol. 60, no. 9, pp. 1779-1792, 2003.

[11] C. M. H. Watanabe, S. Wolffram, P. Ader et al., "The in vivo neuromodulatory effects of the herbal medicine Ginkgo biloba," Proceedings of the National Academy of Sciences of the United States of America, vol. 98, no. 12, pp. 6577-6580, 2001.

[12] A. von Boetticher, "Ginkgo biloba extract in the treatment of tinnitus: a systematic review," Neuropsychiatric Disease and Treatment, vol. 7, pp. 441-447, 2011.

[13] P. Hariharan and T. Subburaju, "Medicinal plants and its standardization-a global and industrial overview," Global Journal of Medicinal Plant Research, vol. 1, no. 1, pp. 10-13, 2012.

[14] X. Yao, E. Shang, G. Zhou et al., "Comparative characterization of total flavonol glycosides and terpene lactones at different ages, from different cultivation sources and genders of Ginkgo biloba leaves," International Journal of Molecular Sciences, vol. 13, no. 8, pp. 10305-10315, 2012.

[15] K. Matsumoto, T. Ohta, M. Irasawa, and T. Nakamura, "Climate change and extension of the Ginkgo biloba L. Growing season in Japan," Global Change Biology, vol. 9, no. 11, pp. 1634-1642, 2003.

[16] S. Yu, Y. Chen, L. Zhang, M. Shan, Y. Tang, and A. Ding, "Quantitative comparative analysis of the bio-active and toxic constituents of leaves and spikes of Schizonepeta tenuifolia at different harvesting times," International Journal of Molecular Sciences, vol. 12, no. 10, pp. 6635-6644, 2011.

[17] P. Kaur, A. Chaudhary, R. D. Singh, Gopichand, R. Prasad, and B. Singh, "Spatial and temporal variation of secondary metabolite profiles in Ginkgo biloba leaves," Chemistry and Biodiversity, vol. 9, no. 2, pp. 409-417, 2012.

[18] K. Matsumoto, "Causal factors for spatial variation in long-term phonological trends in Ginkgo biloba L. in Japan," International Journal of Climatology, vol. 30, no. 9, pp. 1280-1288, 2010.

[19] European Pharmacopoeia, Strasbourg: Council of Europe, vol.1, no. 7, pp. 1828-1829, 2011.

[20] P. Chen, M. Ozcan, and J. Harnly, "Chromatographic fingerprint analysis for evaluation of Ginkgo biloba products," Analytical and Bioanalytical Chemistry, vol. 389, no. 1, pp. 251-261, 2007.

[21] L. Rimkiene, L. Ivanauskas, A. Kubiliene, K. Vitkevicius, G. Kiliuviene, and V. Jakstas, "Optimization of a CUPRAC-Based HPLC Postcolumn Assay and Its Applications for Ginkgo biloba L. Extracts", Journal of Analytical Methods in Chemistry, vol. 2015, Article ID 280167, 2015.

[22] M. Marksa, J. Radušiene, V. Jakštas, L. Ivanauskas, and R. Marksiene, "Development of an HPLC post-column antioxidant assay for Solidago canadensis radical scavengers," Natural Product Research, vol. 30, no. 5, pp. 536-543, 2016.

[23] R. Raudonis, L. Bumblauskiene, V. Jakstas, A. Pukalskas, and V. Janulis, "Optimization and validation of post-column assay for screening of radical scavengers in herbal raw materials and herbal preparations," Journal of Chromatography A, vol. 1217, no. 49, pp. 7690-7698, 2010.

[24] H. Mäkinen, P. Nöjd, H.-P. Kahle et al., "Large-scale climatic variability and radial increment variation of Picea abies (L.) Karst. in central and northern Europe," Trees - Structure and Function, vol. 17, no. 2, pp. 173-184, 2003.

[25] H. W. Linderholm, B. Ø. Solberg, and M. Lindholm, "Tree-ring records from central Fennoscandia: The relationship between tree growth and climate along a west-east transect," Holocene, vol. 13, no. 6, pp. 887-895, 2003.

[26] M. Ellnain-Wojtaszek, Z. Kruczyński, and J. Kasprzak, "Investigation of the free radical scavenging activity of Ginkgo biloba L. leaves," Fitoterapia, vol. 74, no. 1-2, pp. 1-6, 2003.

[27] M. Ellnain-Wojtaszek, Z. Kruczyński, and J. Kasprzak, "Analysis of the content of flavonoids, phenolic acids as well as free radicals from Ginkgo biloba $\mathrm{L}$. leaves during the vegetative cycle," Acta Poloniae Pharmaceutica - Drug Research, vol. 58, no. 3, pp. 205-209, 2001.

[28] S. Sharafzadeh, "Ginkgo (Ginkgo biloba L.), a medicinal tree," International Research Journal of Applied and Basic Sciences, vol. 2, no. 9, pp. 334-338, 2011.

[29] S.-Y. Cheng, F. Xu, and Y. Wang, "Advances in the study of flavonoids in Ginkgo biloba leaves," Journal of Medicinal Plants Research, vol. 3, no. 13, pp. 1248-1252, 2009.

[30] Y.-C. Lee, A. M. Chuah, T. Yamaguchi, H. Takamura, and T. Matoba, "Antioxidant activity of traditional Chinese medicinal herbs," Food Science and Technology Research, vol. 14, no. 2, pp. 205-210, 2008.

[31] B. Shan, Y. Z. Cai, M. Sun, and H. Corke, "Antioxidant capacity of 26 spice extracts and characterization of their phenolic constituents," Journal of Agricultural and Food Chemistry, vol. 53, no. 20, pp. 7749-7759, 2005.

[32] S. Surveswaran, Y.-Z. Cai, H. Corke, and M. Sun, "Systematic evaluation of natural phenolic antioxidants from 133 Indian medicinal plants," Food Chemistry, vol. 102, no. 3, pp. 938-953, 2007.

[33] A. Wojdyło, J. Oszmiański, and R. Czemerys, "Antioxidant activity and phenolic compounds in 32 selected herbs," Food Chemistry, vol. 105, no. 3, pp. 940-949, 2007.

[34] E. Maltas, H. C. Vural, and S. Yildiz, "Antioxidant activity and fatty acid composition of Ginkgo biloba from Turkey," Journal of Food Biochemistry, vol. 35, no. 3, pp. 803-818, 2011.

[35] J. Kobus, E. Flaczyk, A. Siger, M. Nogala-Kałucka, J. Korczak, and R. B. Pegg, "Phenolic compounds and antioxidant activity of extracts of Ginkgo leaves," European Journal of Lipid Science and Technology, vol. 111, no. 11, pp. 1150-1160, 2009. 

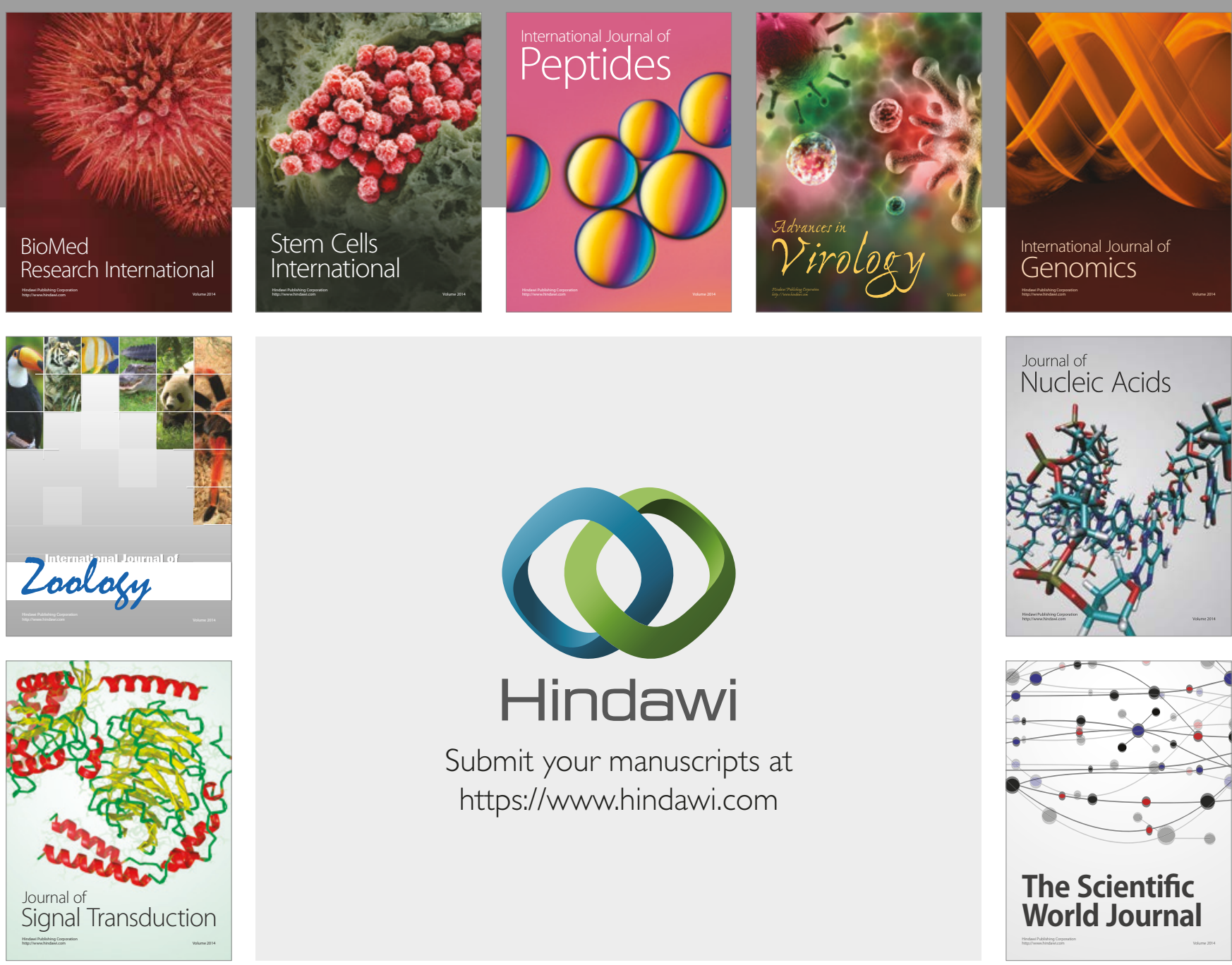

Submit your manuscripts at

https://www.hindawi.com
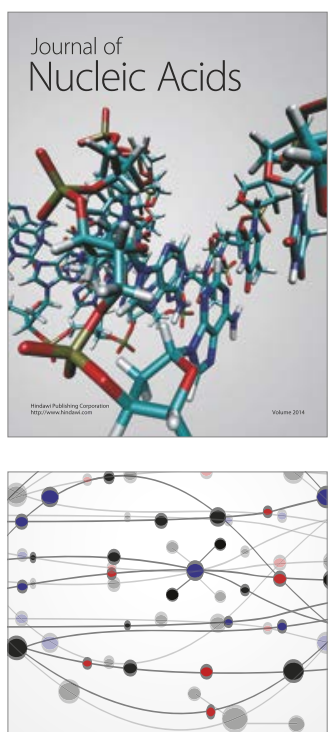

The Scientific World Journal

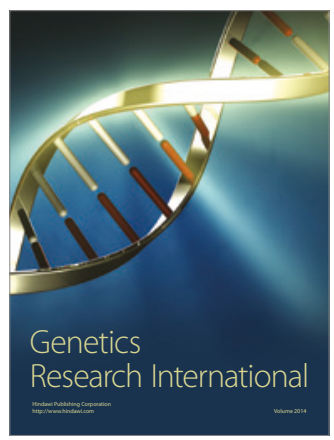

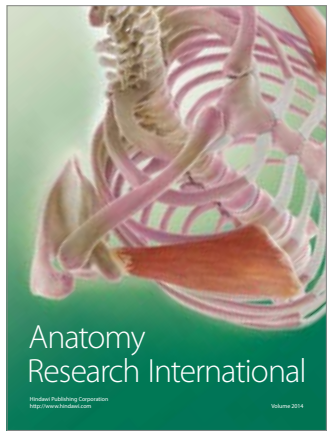

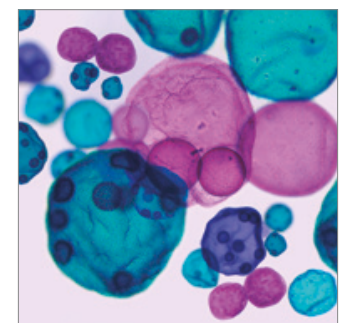

International Journal of Microbiology
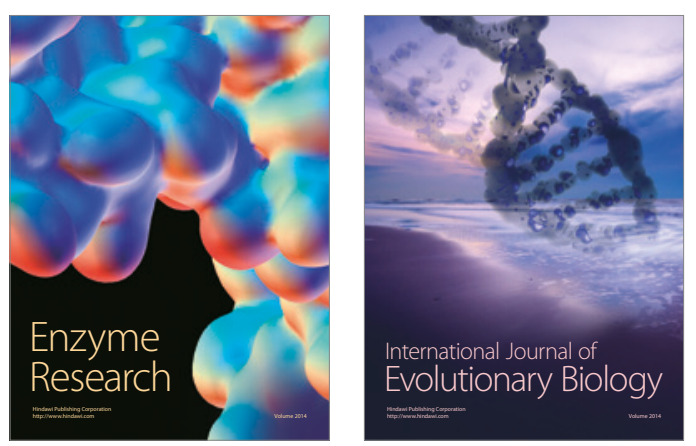
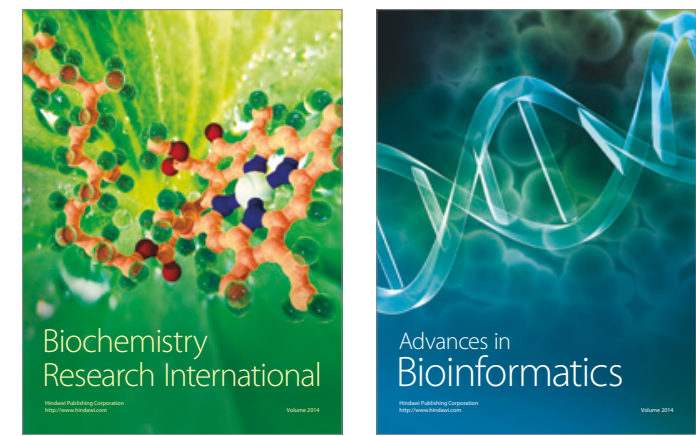

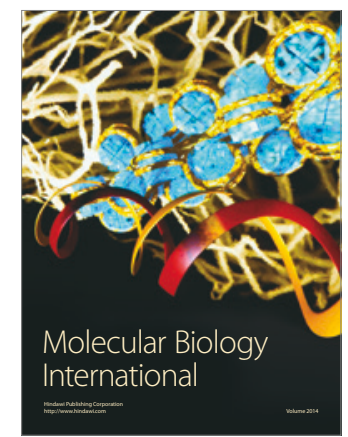

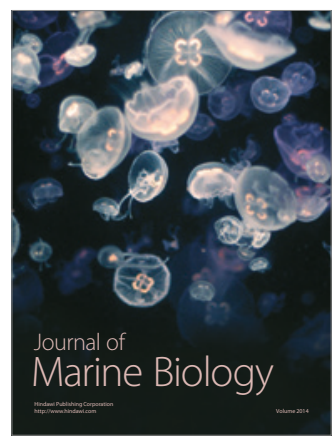

